\section{Wave Velocities in the Outer Part of the Earth's Mantle}

Hrtherto, wave velocities $V$ in the earth's interior have been calculated from the travel times $t$ of earthquake waves in shallow shocks computed as a function of the epicentral distances $\Delta$. This procedure fails if at any depth the velocity $V$ decreases with depth at a rate in excess of $\mathrm{d} V / \mathrm{d} r=V / r$, where $r$ is distance from the centre. In this case a portion of the traveltime curve is formed by the arrival of diffracted waves; if these are misinterpreted as direct waves, incorrect velocities are found not only for the lowvelocity layer, but also (with decreasing e rrors) for all deeper layers. Moreover, discontinuities may be inferred when none actually exists.

In 1914, in a different form, the following equation was developed by S. Mohorovičici ${ }^{1}: V=V^{*} r / R$, where $R$ is radius of the earth, $V$ is velocity at the depth $h=$ $R-r$ of the focus, and $V^{*}$ is apparent velocity $(\mathrm{d} \Delta / \mathrm{d} t)$ at the point of inflexion (distance $\Delta^{*}$ ) of the travel-time curve for longitudinal $(P)$ or transverse $(S)$ waves in a given shock. Apparently it has not been realized that this equation can be used to calculate the velocities of the two waves at a depth corresponding with the focal depth. Neither the time of origin of the shock nor the distance $\Delta^{*}$ enters the calculations. The focal depth $h$ of the shock must be known, and a sufficient number of reliable time observations at distance from about $500 \mathrm{~km}$. less to $500 \mathrm{~km}$. greater than $\Delta^{*}$ must be available for finding $V^{*}$.

About eighty earthquakes were found listed in the International Seismological Summary for which the necessary conditions for application of the method are fulfilled. Niost of them occurred in the Japanese area between 1930 and 1940 at depths from $20 \mathrm{~km}$. to $600 \mathrm{~km}$. For years later than 1940 the Summary has not yet been issued. Data for a few shocks in the eastern and central Mediterranean (depths between $100 \mathrm{~km}$. and $300 \mathrm{~km}$.), in Roumania ( $150 \pm$ $\mathrm{km}$.) and in the Hindu Kush $(250 \pm \mathrm{km}$.) do not indicate any appreciable regional differences in velocity at the depths involved. Average velocities $V$ (longitudinal) and $v$ (transverse) in $\mathrm{km} . / \mathrm{sec}$. , and values of Poisson's ratio $\sigma$ at the depths $h$ in $\mathrm{km}$. are as follows :

$\begin{array}{llcccccccr}h & 50 & 100 & 150 & 200 & 250 & 300 & 400 & 500 & 600 \\ \boldsymbol{V} & 8 \cdot 0 & \ll 7 \cdot 8 & \ll 7 \cdot 9 & 8 \cdot 1 & 8 \cdot 3 & 8 \cdot 5 & 9 \cdot 0 & 9 \cdot 6 & 10 \cdot 2 \\ v & 4 \cdot 45 & \leftarrow 4 \cdot 4 & \ll 4 \cdot 35 & \ll 4 \cdot 4 & 4 \cdot 45 & 4 \cdot 6 & 4 \cdot 95 & 5 \cdot 3 & 5 \cdot 65 \\ \sigma & 0.26 & 0.27 & 0.27 & 0 \cdot 28 & 0.29 & 0 \cdot 29 & 0.29 & 0 \cdot 29 & 0.29\end{array}$

These new values agree well with those which had been found by application of the older method to times of travel of shallow shocks; but they bring out much more prominently the low-velocity layer at depths near $100 \mathrm{~km}$. This had been indicated previously by observations of amplitudes, especially 'shadow zones', at epicentral distances of about $1,000 \mathrm{~km}$. The new velocity data do not indicate any discontinuity within the range of depth given above. A sudden increase in velocity at a depth of about $400 \mathrm{~km}$. has been assumed by some to explain the so-called $20^{\circ}$-discontinuity in the travel-time curve. However, this discontinuity is a consequence of 'ray optics' produced by the low-velocity layer. The actual velocities in the low-velocity layer may be somewhat smaller than those given in the table, since the resulting decreases in $V$ and $v$ possibly exceed the critical rates of 0.13 and $0.07 \mathrm{~km} . / \mathrm{sec}$. per $100 \mathrm{~km}$. respectively. Local temperature or other relatively small differences at the depths involved may result in a decrease of velocity less than the critical rate in one area and in excess of it in another. 'Thus $P$ or $S$ or both may show 'shadow zones' of different extent (including zero) depending on the region, and even noticeable differences in time of travel. This could explain the appreciable local differences in the observed amplitudes of $P$ and $S$ in recorded shocks of a given magnitude at epicentral distances between $500 \mathrm{~km}$. and $2,000 \mathrm{~km}$., even when the velocities at the depths involved are practically the same in all such regions.

Seismological Laboratory,

\section{B. Gutenberg}

Division of the Earth's Sciences,

California Institute of Technology, Pasadena, California. June 20.

${ }^{1}$ Mohorovičc, S., Gerlands Beitr. z. Geophys., 13, 225 (1914). ${ }^{2}$ Gutenberg, B., Bull. Seis. Soc. Amer., 38, 121 (1948).

\section{Band Spectrum of AsH}

Is a letter to Nature, Kimball and Bates ${ }^{1}$ stated that they have succeeded in obtaining the band spectrum of AsH. The spectrum was excited in a carbon arc run in an atmosphere of hydrogen. The lower electrode formed the cathode of the arc and contained the arsenic. Two bands with origins at $32,380 \cdot 2 \mathrm{~cm}^{-1}$ and $31,639.9 \mathrm{~cm} .^{-1}$ were observed and attributed to AsH. The lines of the band at $32,380 \cdot 2$ $\mathrm{cm} .^{-1}$ are represented by the formula

$$
\begin{gathered}
\gamma=32,380 \cdot 18-11 \cdot 186 m-4 \cdot 47 m^{2}+ \\
0 \cdot 0485 m^{3}+0 \cdot 01027 m^{4} .
\end{gathered}
$$

We have tried to photograph the bands mentioned by Kimball and Bates but without success, although a large range of excitation conditions has been used.

It seems probable that Kimball and Bates have been confused by the $P$ and $R$ branches of the ${ }^{2} \Sigma-{ }^{2} \Pi$ system of $\mathrm{CH}$. Using the frequencies of the lines for the $R_{1}$ and $R_{2}$ branches of the $(0,0)$ CH band, as listed by Heimer ${ }^{2}$, a close fit of the alternate lines is obtained with the lines calculated from the formula given by Kimball and Bates. This is illustrated in the table for a number of lines.

\begin{tabular}{|c|c|c|c|}
\hline $\begin{array}{c}R \text { branch } \\
\text { of } \mathbf{A s H}\end{array}$ & $\begin{array}{l}R_{2} \text { branch } \\
\text { of } \mathrm{CH}\end{array}$ & $\begin{array}{c}P \text { branch } \\
\text { of AsH }\end{array}$ & $\begin{array}{c}R_{1} \text { branch } \\
\text { of } \mathrm{CH}\end{array}$ \\
\hline $\begin{array}{r}32,364 \cdot 6 \\
340 \cdot 5 \\
308 \cdot 5 \\
269 \cdot 6 \\
224 \cdot 9 \\
175 \cdot 8 \\
124 \cdot 0 \\
071 \cdot 3 \\
019 \cdot 9\end{array}$ & $\begin{array}{r}32,366 \cdot 4 \\
340 \cdot 6 \\
307 \cdot 6 \\
268 \cdot 4 \\
224 \cdot 6 \\
177 \cdot 2 \\
126 \cdot 6 \\
073 \cdot 7 \\
019 \cdot 3\end{array}$ & $\begin{array}{r}32,386 \cdot 9 \\
384 \cdot 4 \\
373 \cdot 0 \\
352 \cdot 9 \\
324 \cdot 6 \\
289 \cdot 1 \\
247 \cdot 3 \\
200 \cdot 6 \\
150 \cdot 5\end{array}$ & $\begin{array}{r}32,388 \cdot 5 \\
384 \cdot 2 \\
377 \cdot 1 \\
355 \cdot 7 \\
325 \cdot 7 \\
289 \cdot 1 \\
247 \cdot 5 \\
201 \cdot 4 \\
152 \cdot 1\end{array}$ \\
\hline
\end{tabular}

Comparison of the AsH lines with alternate CH Jines

The other AsH band mentioned by Kimball and Bates was probably confused with the $P$ branches of the 0,0 band of $\mathrm{CH}$ and the $Q$ branch of the $1, \mathrm{I}$ band. The 1,1 band of $\mathrm{CH}$ forms a $Q$ head at the approximate frequency of the AsH head mentioned by Kimball and Bates.

Pearse and Gaydon ${ }^{3}$ have directed attention to the fact that the band attributed to $\mathrm{As}_{2}$ by Kimball and Bates is probably identical with the $Q$ branches of the $0,0 \mathrm{CH}$ band. 